\title{
El nacionalismo vasco y España: reflexiones en torno a un largo desencuentro
}

\author{
LUDGER MEES (UPV-EHU)
}

En 1995 se celebró el centenario de la fundación del Partido Nacionalista $V a s c o$, núcleo y espina dorsal del movimiento social articulado y liderado por Sabino Arana a finales del siglo XIX ${ }^{1}$. EI PNV es, por tanto, junto con el PSOE, el partido político más antiguo del sistema político español, pero también, y a pesar de su larga historia, es seguramente el partido político que mayores problemas ha tenido a la hora de definir su ubicación en este sistema. A lo largo de su trayectoria histórica, la posición del nacionalismo vasco hacia España ha oscilado entre los polos opuestos de una negación y un rechazo total y absoluto por un lado y una cooperación crítica desde un prudente distanciamiento por otro, y lo sigue haciendo hoy en dia si consideramos las distintas y enfrentadas fracciones del nacionalismo vasco actual. Creo no exagerar cuando afirmo que esta ambigüedad, esta falta de definición, este navegar entre diferentes puertos acompañado por tremendas dudas a la hora de decidir hacia cuál de ellos dirigir el rumbo de la embarcación no encuentra simil en los otros dos nacionalismos históricos del Estado español: el catalán y el gallego. A lo largo de las reflexiones siguientes trataré de descubrir algunas de las claves que a mi modo de ver ayudan a explicar esta particular y centenaria historia del nacionalismo vasco, una historia que habrá que analizar en sus dos dimensiones principales: la externa, formada por

\footnotetext{
Este texto es la versión elaborada y ampliada de una conferencia que dí en el seminario "¿A qué llamamos España?" organizado en agosto de 1996 en el marco de los cursos de verano de la Universidad Internacional Menéndez Pelayo en Santander. Agradezco a los participantes del seminario, y especialmente a su director, Javier Tusell, las múltiples críticas y sugerencias recibidas. Santiago de Pablo se tomó la molestia de leer un primer borrador de este artículo. Sus comentarios han sido, como siempre, interesantes y estimulantes a la hora de redactar la versión definitiva de este ensayo. Para facilitar su lectura, he prescindido del aparato crítico, añadiendo para el lector interesado en la profundización de la temática una breve bibliografía básica.
} 
las magnitudes socioeconómicas, políticas y culturales del proceso de modernización del Estado liberal en España, así como sus características en el País Vasco; y la segunda dimensión, la interna, que define la estructura de la propia sociedad vasca y la posición que ocupa el nacionalismo en su seno.

\section{I. $1876-1936$}

En cuanto a sus orígenes, los problemas del nacionalismo vasco con España no son otra cosa que consecuencias de los problemas de España y sus gobiernos con el Pais Vasco y las otras naciones y regiones del Estado, o, para decirlo de una forma más académica, utilizando el lenguaje aséptico de la politologia norteamericana: son frutos del notable desfase existente en la España decimonónica entre el state-building, concluido definitivamente en 1876 o - si se quiere- en 1898, y el lento e inacabado nation-building. El portador del proyecto nacional español fue un liberalismo débil y territorialmente fraccionado que para imponer su modelo de Estado y sociedad tuvo que recurrir más a las armas que a alianzas sociales y a la labor cohesionadora de las instituciones. La tarea de convertir "paisanos en españoles", por parafrasear el título del clásico estudio de Eugen Weber en Francia ("Peasants into Frenchmen»), cojeó desde el principio, puesto que algunos de los principales vehículos que en el país vecino y otros países habian facilitado la integración y cohesión de los ciudadanos por encima de las tradicionales lealtades y autoadscripciones preestatales, sólo funcionaron de manera deficiente.

En primer lugar, la miseria de la educación pública, víctima de la deplorable situación de las fianzas en un Estado en quiebra continua, no permitió la realización de proyectos bastante ambiciosos, iniciados con la apropiación del primer Reglamento General de Instrucción Pública en 1821. La Iglesia, muy vinculada al Antiguo Régimen, seguia controlando gran parte de las aulas y desde luego no tenia ningún interés en perder su capacidad de maniobra y convertirse en brazo ejecutor de un proyecto político e ideológico liberal al que se sentía si no opuesta, al menos distante.

Tampoco la otra gran idea que desde los tiempos de la Revolución Francesa había penetrado con fuerza en las masas populares de los países europeos contribuyendo a su vertebración en torno al nuevo concepto de la nación, cuajó en España: la idea del ejército nacional como el conjunto de los ciudadanos en armas. Es cierto que algunos de sus estudiosos, sobre todo en Francia, a veces se han dejado guiar por una visión un 
tanto idílica de este mecanismo de transformación de los ciudadanos armados en fervientes defensores de su patria y de la idea nacional. No deberiamos olvidar que también en Francia las desigualdades sociales pasaban enormemente en el reclutamiento y el servicio militar y que el atractivo de la idea nacional era a menudo mucho menos importante que la coerción y las represalias. Ahi está, por citar sólo un ejemplo, el caso de las sublevaciones campesinas en el oeste de Francia durante la Gran Revolución, que sobre todo en el caso de la Vendée condujeron a unas dramáticas consecuencias que desacreditaron en esos territorios franceses durante décadas él proyecto político de los revolucionarios parisinos. Pero es cierto también que en España la idea del ejército nacional nunca llegó a ser más que una broma de mal gusto, ya que nadie tenia que in: tegrarse en el servicio militar, si no quería alistarse y tenía medios económicos suficientes para acreditar estos deseos, de manera que el ejército seguía siendo un coto reservado de las clases humildes. No fue hasta 1912 que el gobierno, entonces presidido por Canalejas, se vió obligado por decreto esta práxis escandalosa, una y otra vez denunciada por la izquierda.

En tercer lugar conviene subraya que ni siquiera las posibilidades de participación, y en consecuenica de integración, que ofrecía el parlamentarismo liberal con sus - sobre el papel- notables ingredientes de democracia formal, se aprovecharon en España. El sistema del turno pacífico, las mayorías prefabricadas y las omnipotentes redes clientelistas fueron obstáculos insuperables que se oponían a cualquier estrategia de construir la cohesión e integración del nuevo Estado-nación. La cohesión funcionó a nivel de las élites de poder, pero todo ello a costa de la marginación de amplios sectores de la sociedad, tanto del republicanismo y del carlismo, como de las diferentes organizaciones de la clase obrera, o de los nacionalismos periféricos.

Por lo tanto, fue la debilidad del liberalismo español y su capacidad de constituirse en un movimiento nacionalista cohesionador del nuevo Estadonación, la que proporcionó las respuestas de los nacionalismos periféricos contra un reparto de poder realizado sin el consentimiento y participación de sus élites.

En el País Vasco, el proceso del state-building español tuvo unas connotaciones aún más espectaculares. Probablemente en ningún otro territorio del nuevo Estado este proceso tuvo unos ingredientes tan fuertes de coerción como en las provincias vascas, en las que la sensación de padecer una ocupación militar se prolongó aún después de 1876 durante bastante tiempo. Tras la derrota definitiva del carlismo, la abolición radical 
de los Fueros suscitó las iras incluso de los liberales vascos, formándose con el Fuerismo un amplio movimiento prenacionalista que se nutría de prácticamente todos los sectores políticos y sociales de la sociedad vasca. La concesión de los Conciertos Económicos logró su objetivo dividiendo al Fuerismo e integrando a las élites económicas vascas en el consenso constitucional de la Monarquía restauracionista. Con el carlismo militarmente vencido y políticamente impotente y el Fuerismo reducido a los pequeños e inoperantes grupos de los intransigentes, en las provincias vascas se gestó un extenso terreno de descontentos y frustrados, un terreno virgen políticamente no cultivado. Ahora bien, sabemos por la teoría sociológica que una frustración y una sensación de privación por intensiva que sea, por si sola normalmente no suele desencadenar un movimiento social. Son las nuevas expectativas generadas por la movilización de recursos y alteraciones de la estructura de oportunidades políticas las que actúan como catalizadores de los movimientos sociales. Este es el caso de Bizkaia a partir de la década de 1880, cuando comienza un acelerado y brusco proceso de industrialización que en pocos años va a cambiar radicalmente la estructura económica, social y cultural de la provincia, lo que más tarde ocurrirá de forma más pausada y con consecuencias menos traumáticas y disruptivas también en Gipuzkoa. A la vez, el sufragio universal masculino abrió las puertas a una nueva política de masas que paulatinamente iba a, si no sustituir, al menos competir con la tradicional política de notables. Los nacionalistas vascos aprovecharon estas nuevas oportunidades en un momento en el que el Estado vio dramáticamente agudizada su crisis por la pérdida de las últimas colonias. Nacido entre los núcleos pequeño burgueses y pronto liderado por las nuevas clases medias, el nacionalismo vasco se irá convirtiendo en un amplio movimiento popular interclasista en cuyo seno cohabitaban diferentes sectores e intereses y cuyo difícil equilibrio se construyó sobre un difuso sentimiento de oposición particularista ante todo los foráneo, extraño, y supuestamente antivasco.

El éxito de Sabino Arana radica precisamente en su renuncia a construir un discurso clasicista en beneficio de la evocación de una tradición cultural y política hondamente arraigada entre los vascos de diferentes clases sociales. La aportación de Arana consiste en ofrecer una nueva lectura de esta tradición, una lectura que por la virulencia de las circunstancias en las que se confeccionaba será igualmente radical y extremista y que contenía, como todos los nacionalismos, grandes dotes de imaginación e invención. El simbolo de toda maldad y perversión que se habia adueñado de Euskadi era España y sus agentes los barbudos y sucios inmigrantes socialistas así como los vendepatrias españolistas entre los 
capitalistas vascos que, guiados por su egoísmo materialista, eran los verdaderos responsables de esa invasión maketa.

Pero no es sólo la gravedad de las circunstancias (fracaso del nationbuilding; imposición militar; brusquedad del proceso de modernización) la que en mi opinión explica la radicalidad del discurso nacionalista y con ello el contundente rechazo de todo lo que oliera a español. La radicalidad y el extremismo son también figuras retóricas que tratan de compensar la propia debilidad del nacionalismo vasco. La nueva sociedad vasca, sobre todo la vizcaina, que se genera a partir de finales del siglo XIX es una sociedad altamente fragmentada y polarizada alrededor de tres bloques: el nacionalista, el liberal y socialista, así como el monárquico conservador de ambas tendencias: la alfonsina y la carlista. Antes de la Guerra Civil, los nacionalistas no consiguieron ni en sus fases de máxima movilización como entre 1917 y 1919 o en 1933/34, imponer su proyecto y alcanzar una clara hegemonía política sobre sus oponentes, a los que además unían unos fuertes lazos de oposición común al nacionalismo vasco. Este nivel de fragmentación y polarización era tan elevado que los escasos intentos de construir proyectos mediadores entre los bloques tuvieron que morir asfixiados o, si lograban sobrevivir, lo hacían enfermizos y débiles. Así, los esfuerzos que Francisco de Ulacia y otros emprendieron entre 1910 y 1913 con el afán de acercar el nacionalismo al republicanismo según el modelo de la "Unión Federal Nacionalista Republicana" en Cataluña no consiguieron abrirse paso ni en el mundo nacionalista dominado por un clericalismo a ultranza ni en el campo de la izquierda liberal reacia ante cualquier iniciativa proveniente del lado nacionalista. Años después, entre 1917 y 1919, un nuevo intento en esta dirección se saldó con la publicación de las reflexiones de nacionalistas críticos como Landeta, Sarria o Belausteguigoitia en la revista cultural Hermes. No tuvieron mayores consecuencias aunque en estas contribuciones periodísticas redactadas al calor de la primera campaña autonómica se planteara probablemente por primera vez en la historia del nacionalismo vasco seriamente $y$ a nivel teórico la relación entre el Estado español y la futura Euskadi autónoma y autogobernada. Nuevamente, el puente tendido por parte de estos nacionalistas desidentes acabó en tierra de nadie, lo mismo que el socialismo autonomista defendido por líderes como Toribio Echevarría o José de Madinabeitia desde el feudo del socialismo guipuzcoano de Eibar. Fue la euforia que acompañó el advenimiento de la II República la que ayudó a madurar todos estos esfuerzos precedentes y a fundar Acción Nacionalista Vasca, un partido nacionalista, laico, republicano y autonomista. Sin embargo, ni en el nuevo contexto de la República la ya tradicional polarización de la sociedad vasca disminuyó notablemente, de ma- 
nera que el impacto que obtuvo ANV en el sistema de partidos vasco fue bastante reducido.

Como se ve, antes de 1936 , el nacionalismo es una ideología y un movimiento importante de la sociedad vasca que sin embargo no consigue superar sus propios límites. Lejos de realizar sus pretensiones hegemónicas, no sólo no consigue penetrar en sectores no vinculados a la propia comunidad nacionalista, sino que debe observar cómo estos sectores reaccionan con mayores movimientos de hostilidad a cada incremento de poder nacionalista, sea lo reducido que sea. Esta debilidad y esta falta de flexibilidad política y social que caracteriza a la sociedad vasca anterior a la Guerra contribuyen a petrificar el discurso nacionalista que prácticamente desde tiempos de Sabino Arana no va a conocer modificación alguna en lo que a la definición de las relaciones entre España y Euskadi se refiere.

¿Cuál es, pues, esta definición? ¿A qué aspira el partido fundado por Sabino con su política? La respuesta es simple: esa definición no existe y lo que encontramos en su lugar es una calculada ambigüedad programática que da cobijo a opciones de todo tipo, desde el independentismo puro y duro hasta el autonomismo moderado. Como es sabido, esta ambigüedad es una herencia que dejó Sabino cuando poco antes de su prematura muerte en 1903 sembró el pánico entre sus seguidores más radicales planteando públicamente la convenencia de fundar una «Liga de Vascos Españolistas" y olvidarse — por lo menos a nivel táctico y estratégico- de los proyectos independentistas que hasta entonces habian dominado su discurso. Tras la muerte del fundador se desató una feroz lucha por el poder en el partido, durante la cual cada bando se aferró al Sabino de su gusto, es decir, al separatista radical o al autonomista moderado. Nadie se atrevía a entrar realmente en el fondo del debate que no consiguió salir de la sombra del gran maestro por todos venerados. En varias ocasiones la tensión subió tanto que la ruptura parecía inevitable. Al final, y puesto que ninguna de las dos fracciones pudo prescindir de la otra sin hipotecar gravemente el futuro del movimiento, se llegó a un compromiso cuya principal virtud radica en el hecho de dejar las cosas más o menos como estaban. El primer manifiesto programático del Partido Nacionalista Vasco refrendado en asamblea general a finales de 1906 fija como objetivo de la polí. tica nacionalista no la independencia ni la autonomía, sino la «plena reintegración foral". Puesto que se omitía cualquier aclaración sobre el potencial significado jurídico de la restauración de los Fueros en el contexto completamente nuevo de la Monarquía alfonsina, cada nacionalista quedaba libre para interpretar esa fórmula mágica a su antojo. Es precisamente esta indefinición criticada por Angel Zabala, el sucesor de Sabino 
Arana a la cabeza del partido, la condición sine qua non de la cohesión del partido. Mientras que Zabala rechazó el programa porque en su opinión, como decía, "se ocultaba lo principal», dimitiendo de su cargo, la gran mayoría de los afiliados 10 aprobó exactamente por esta razón. Esta escueta referencia a los Fueros será la única información programática que el PNV iba a facilitar durante las próximas décadas sobre su máxima aspiración política. Esta deliberada indefinición permitía tanto lecturas separatistas como autonomistas y abría paso a una política cada vez más pragmática y posibilista, a la que sin embargo no faltó nunca este ingrediente milenarista, esta esperanza de que la política del día a día en el fondo no era más que un cúmulo de innumerables eslabones de una larga cadena que inevitablemente llevaría a la recuperación de esa edad de oro de la que los vascos supuestamente habían gozado antes de la abolición foral.

Con todas las criticas que se pueden verter sobre esta calculada ambigüedad programática, no hay que olvidar sus consecuencias en mi modo de ver positivas tanto para el propio nacionalismo como para la democracia en el Estado: una vez descartada la amenaza de escisión y cohesionado el movimiento en torno a un programa, el PNV en la práctica dejó detrás sus veleidades anti-sistema y su postura de ciego rechazo a todo 10 español para adoptar una actitud mucho más activa y participativa en el marco de la política del Estado. Impensable todavía unos pocos años antes, en 1907 los nacionalistas aceptaron la designación por Real Orden para alcalde de Bilbao de un afiliado suyo a instancias del gobierno Maura. También el tradicional rechazo de una activa participación en las instituciones españolistas como las Cortes iba perdiendo poco a poco atractivo en el movimiento nacionalista, de manera que en 1918, la primera candidatura peneuvista a las elecciones generales apoyada por todos los sectores del partido arrasó en Bizkaia consiguiendo asimismo la elección de un representante en Gipuzkoa y en Navarra.

Evidentemente, esta mayor implicación en la política estatal demostraba diariamente que Euskadi no era una pequeña isla aislada del resto del mundo, sino un territorio insertado - con o contra su voluntad- en un marco político concreto del que dependía su presente y su futuro. Los líderes nacionalistas vieron cada vez más claro que no bastaba luchar por obtener las mayores cotas de poder posibles en las propias provincias vascas y que todas las mayorías regionales no servian para mucho si no dejaban algún sustrato también en Madrid. Este es el razonamiento que va a inspirar toda la política nacionalista a partir de los años de la I Guerra Mundial y que dará pie no a la superación de la ambigüedad doctrinal, pero sí a la concreción de los objetivos políticos por la vía de los hechos: será la autonomía regional la que se coloca en el centro de las actividades 
nacionalistas y la que de facto iba a sustituir la reclamación de reintegración foral.

El primer y poco conocido paso en esta dirección se da ya en 1914 cuando en el diario nacionalista Euzkadi se comenta la constitución de la «Mancomunidad de Cataluña» que por su carácter de reforma meramente administrativa desde luego ni de lejos era equiparable a un Estatuto de Autonomia. Sorprendentemente, los comentarios que difunde Euzkadi no son del todo negativos, adelantándose el argumento que más adelante iba a servir para legitimar la política gradualista del partido ante sus sectores más radicales: soluciones transitorias como la Mancomunidad había que aceptarlas siempre y cuando allanaran el camino hacia la recuperación de los derechos históricos, es decir, la recuperación de los Fueros.

No ha de extrañar, pues, que tres años más tarde, después de que ese primer globo sonda lanzado por el diario nacionalista ente los afiliados no causaran mayores problemas, la nueva Diputación nacionalista de Bizkaia iniciara la primera campaña autonómica del País Vasco con un programa que definía el objetivo a conseguir en términos de Mancomunidad Vasca. Empujados por la euforia nacionalista que se habia adueñado de Europa, los nacionalistas vascos consiguieron por lo menos inicialmente poner en marcha y liderar un amplio movimiento autonomista apoyado por las Diputaciones de Gipuzkoa y Alava, sacrificando algunos de sus principios básicos. Así, la resolución aprobada por las tres entidades vascas en julio de 1917 solicitó al gobierno "una amplia autonomía» para las diputaciones y los municipios vascos, todo ello «dentro de la unidad de la nación española», una concesión hasta entonces impensable en el campo nacionalista y aparentemente de tanta envergadura que el diario Euzkadi eliminó la palabra «española» en su reproducción del texto, argumentando que esta cláusula era un sinsentido ya que no existía ninguna nación española y por consiguiente el reconocimiento formal de la misma carecía de significado y era un mero instrumento táctico para mantener la imprescindible unidad del movimiento autonomista.

A pesar de estas importante concesiones y pese a que entre 1917 y 1919 los nacionalistas vascos hicieran todo lo posible para presentarse como un firme garante de la estabilidad política y social aliado con un gobierno que en 1917 pasó por el punto álgido de su larga crisis, las tradicionales élite de poder no consintieron la más mínima alteración del status quo. Con la vuelta de Maura al poder a principios de 1919, no sólo se cerraron todas las puertas a las reivindicaciones autonómicas vascas, sino que se inició un nuevo período de acoso al nacionalismo vasco en el terreno político y judicial con una virulencia desconocida hasta entonces. 
Es durante estos años de continuo enfrentamientos entre el nacionalismo vasco y la derecha monárquica cuando entre los jeltzales da comienzo un largo proceso de reorientación política que años más tarde acabará en la convicción de que la izquierda era un aliado más fiable para la consecución de la autonomía vasca que la derecha. Este proceso no fue unidireccional y todavía tuvo que pasar la prueba de la dura confrontación entre nacionalismo vasco y fuerzas republicanas durante el primer bienio de la República, pero la represión sufrida tanto por los nacionalistas como por la izquierda durante el bieno negro contribuyó a fraguar una alianza, cuyo resultado fue el Estatuto de 1936 y la implicación de los nacionalistas vascos en la defensa de la República durante la guerra. Es cierto que aún después de la aprobación del Estatuto del PNV seguía manteniendo su tradicional indefinición con respeto a la ubicación política del País Vasco en el marco del Estado, ya que el argumento de la autonomia como un primer paso a la restauración foral seguía escuchándose por parte de varios de sus lideres y son muchas las citas que podríamos aportar aqui en este sentido. Es cierto también que el PNV no habia aprobado la Constitución de 1931, sobre todo debido a la regulación de la cuestión religiosa, y que por tanto mantuvo su distanciamiento hacia el régimen republicano y en general, hacia la política española. Pero no es menos cierto que lo que realmente importa, que es la práctica política del partido, siguió por la via iniciada en 1917 de un gradualismo posibilista centrado en la consecución de la autonomía vasca, aunque, como dijera Engracio de Aranzadi en 1936, no fuera más que "un poco de libertad en relación con la libertad nacional perdida aquí en 1839 ", pero este poco de libertad, asi sigue Kizkitza, "ante la realidad actual vasca, significa una inmensa posibilidad de restauración nacional» (Euzkadi, 4.7.1936). De esta forma, la lucha por la autonomía había convertido al PNV de hecho -y pese a la voluntad manifiesta de algunos de sus líderes y la obstrucción de la derecha monárquica - en un partido integrado en el sistema político republicano.

\section{II. $\quad 1937-1975$}

La Guerra Civil y la larga dictadura franquista, sin embargo, pusieron fin de forma dramática a este todavía poco consolidado proceso de aproximación y apertura hacia una interpretación más realista y menos visceral de lo que para los nacionalistas vascos suponía España. Aún tras la derrota militar y la desvinculación de la defensa de la República que los nacionalistas, o por lo menos algunos de sus máximos líderes, rubricaron 
en el Pacto de Santoña, el gobierno republicano del exilio seguió siendo durante años una obligada referencia para los nacionalistas vascos. Prueba de ello son, entre otras cosas, la permanencia de Manuel de Irujo como ministro del gobierno hasta después de la II Guerra Mundial, asi como los numerosos intentos de mediación entre los diferentes y enfrentados sectores del gobierno republicano en el exilio que no se cansaba de emprender José Antonio de Aguirre, lehendakari vasco y hombre que gozaba de gran prestigio entre prácticamente todas las fracciones republicanas, intentos que conocemos gracias a varios testimonios, entre ellos los de Indalecio Prieto. El mantenimiento de la unidad republicana y del compromiso autonómico a toda costa por un lado, y la implicación del nacionalismo vasco en la lucha aliada contra Hitler por el otro, -estos fueron los dos ejes en torno a los que pivotó la política jeltzale durante el primer decenio posterior a la victoria franquista en el frente del norte-. Una vez vencido Hitler -asi podría resumirse la esencia de la mayoria de los mensajes y declaraciones públicas de Aguirre-, los aliados reestablecerian también la legalidad republicana en España y con ello la amplia autonomía que los vascos habían disfrutado durante ocho meses.

Esta esperanza, y con ello toda una estrategia y un concepto político, quedaron en agua de borrajas cuando a partir de 1947 empezó a quebrantarse la gran coalición anti-Hitler y la Guerra Fría fracturó al mundo en dos bloques opuestos y enfrentados. En este nuevo escenario histórico no hubo espacio ni para el gobierno republicano ni para el vasco. Franco, en cambio, logró transformar su papel de malvado lobo feroz en el de bella princesita cortejada por los elegantes y poderosos señores dueños de la democracia occidental. La España interpretada por Franco se había convertido en la única obra de la cartelera y sus actores en tierras vascas no se salieron un ápice del guión que preveía un duro castigo a las "provincias traidoras".

De esta forma, la fatalidad del devenir histórico se había encargado por una parte de enviar a la hoguera a las tímidas apuestas de nacionalistas vascos como Irujo, Aguirre o Landaburu en favor de la otra España, de la España democrática, republicana y sobre todo la España respetuosa con el hecho diferencial vasco. Por otra parte, esta nueva realidad franquista superaba aún con creces las peores imágenes que los nacionalistas más radicales desde los tiempos del primer Sabino Arana habían dibujado de España como malvado monstruo y eterno opresor de todo lo vasco. La prematura muerte de Aguirre en 1960 fue la culminación de la aguda crisis del nacionalismo vasco que se había quedado sin su carismático líder y sin proyecto político viable alguno. Es en este contecto, marcado también por el comienzo de la segunda gran oleada de modernización económica y 
social de las provincias vascas, en la que surge el nuevo nacionalismo radical y toma el relevo en la lucha por la liberación de Euskadi.

Como se sabe, la verdadera ruptura entre nacionalismo nuevo y viejo no llega hasta años después de la fundación de ETA en 1959. Fue en 1963, cuando la aparición de la obra titulada Vasconia y escrita bajo seudónimo por el que será el máximo ideólogo del nuevo nacionalismo, Federico Krutwig, dio comienzo a una nueva fase en la historia del nacionalismo vasco marcada por la ruptura de varios tabúes. En primer lugar, Vasconia significó la primera recepción positiva del marxismo en la historia del nacionalismo vasco. Para Krutwig, entre la clase obrera y la burguesía vascas no existía únicamente una contradicción de clase, sino también nacional, ya que el capital vasco colaboraba objetivamente con el colonizador español. En segundo lugar, supuso la introducción innovadora de conceptos y teorias discutidas a la sazón por hombres como Guy Héraud y otros etnolingüistas europeos. Para la confección de su cóctel ideológico, Krutwig se valió en tercer lugar de las teorías provenientes de las luchas anticoloniales muy en boga durante los 50 y 60 , para defender y teorizar - y éste es el cuarto punto-, con citas de Clausewitz, Ho-Tschi-Min y Mao sobre la necesidad de la lucha armada para alcanzar la libertad de Euskadi. No fue la plausibilidad teórica de los ejemplos tercermundistas la que explica su atractivo, sino el hecho de que las tesis de Krutwig parecian ajustarse como un guante a las vivencias diarias de la población vasca sumergida nuevamente en un brusco proceso de cambio social y expuesta a la persecución y represión no sólo política, sino también cultural. De la totalidad de once estados de excepción proclamados por el régimen entre 1956 y 1975, diez afectaron a Bizkaia y/o Gipuzkoa, de manera que los habitantes de las provincias costeras vascas vivieron de estos veinte años algo más de 4 años y medio de facto en una situación de ocupación militar con cotas de detenciones extremadamente altas. La definición de Euskadi como una colonia de la españa franquista, por absurda que resultara desde otros puntos de vista, tuvo todas las posibilidades de calar hondamente entre los afectados, teniendo además la virtud de senalar por fin una vía aparentemente factible para salir de la situación de pasividad y desesperanza en la que se encontraba el nacionalismo del exilio. Para Krutwig, la guerra civil había puesto de relieve el tremendo error de los regionalistas vascos que habían confiado en la vía autonomista dentro de la II República:

"Ellos habian logrado algo. No hay duda de que poseian un sistema autonómico en la República española. Y como esto, aunque poco, era algo, propio de ellos, lo defendias a capa y espada ante la nueva generación que 
empezaba a pedirles cuentas de su inoperancia. Lo que no se habían dado cuenta es que el Estatuto era miembro de un cuerpo que se llama "II República Española" y que, muerta ésta, con ella se había podrido en la tumba el Estatuto vasco. Estaban, pues, queriendo mantener en vida al miembro de un cadáver putrefacto" (Sarrailh, 11).

Por tanto, no habia nada que hacer, ni con el gobierno vasco en el exilio, ni con el Estatuto, ni con la República. La lucha iba en contra de España como agente de la explotación cultural y económica del Pueblo Vasco:

"La persecución nacional del pueblo vasco alcanza tales limites que el más imbécil puede verlas con claridad. Así, pues, junto a la expoliación cultural del pueblo vasco se une en la parte sometida a la ocupación militar de las fuerzas armadas de la opresión española un robo tan descarado que no hay formas de ocultar» (ibid., 332).

Los representantes del gobierno regionalista en el exilio, y especialmente el nuevo lehendakari Leizaola, al fin y al cabo no eran más que colaboradores de esta España opresora, tal y como se puede ver en la siguiente durísima crítica a Leizaola por no enseñar a sus hijos el euskera, una crítica que en su día levantó ampollas entre los circulos nacionalistas vascos:

"Mi espanto fue tremendo cuando me entere que el propio Presidente, Sr. Leizaola, en realidad no era más que un colaborador gratuito de los enemigos del Pueblo Vasco (...). Pense que en realidad en los pueblos de la Europa central, un falso nacionalista que cometiese tal pecado de lesa patria hubiese merecido ser fusilado de rodillas y por la espalda, mientras que nosotros aún lo teníamos por presidente de un gobierno, que el ingenuo pueblo vasco cree Gobierno Nacional del Pueblo Vasco, la entidad que nos iba a traer la independencia a nuestra Patria. Entonces comprendí claramente cómo ese Gobierno no podia ser otra cosa que un cadáver maloliente, un ente putrefacto, que no tenia ningun valor para la idea nacronai vasca y sólamente sirve para ofuscar al pueblo ingenuo. Es decir, que es un ente que en realidad conviene que desaparezca cuanto antes" (ibid., 12). ya que - tal y como profetiza Krutwig en otro lugar de su libro"la causa de la independencia vasca es algo inevitable por Ley natural" (pág. 332).

En esta visión de España, una visión basada en el primer Arana, contemplada desde una óptica marxista-leninista y anticolonialista, ampliada por el recurso a la lucha armada y cuyo mejor aval era la realidad franquista, la que - ante el aparente fuera de juego político del nacionalismo moderado- dominaba en el nacionalismo vasco hasta que la muerte del dictador abriera nuevas perspectivas. 


\section{1975-1996}

Si esta tesis es cierta -y ahí nos esperan todavía muchas horas de trabajo en los archivos del Gobierno Vasco y del PNV del exilio aún no abiertos al público-, para mi no dejan de ser sorprendentes dos hechos políticos de la transición y la consolidación democrática en el País Vasco. Cabe destacar en primer lugar que la hegemonia durante más de una década de esta imagen absolutamente negativa de lo que significaba España para los nacionalistas vascos, así como la popularidad que las actividades de ETA habian conseguido no sólo entre los sectores nacionalistas de la sociedad, no se tradujeron en un radical trasvase de las lealtades políticas desde las organizaciones vinculadas y teóricamente desprestigiadas del nacionalismo viejo hacia las agrupaciones de la nueva izquierda nacionalista radical. EI PNV resucitó de las cenizas con una velocidad realmente abrumadora y alcanzó - y sigue alcanzando - unas cotas de influencia y poder que no tienen simil en las fases anteriores de su historia. Lo mismo cabe decir en otro contexto del sindicato nacionalista ELA. Parece, por tanto, que también en este caso las largas tradiciones culturales de adhesión y lealtad a una organización y a un proyecto político pesaban mucho más en la memoria colectiva que alteraciones más o menos súbitas del paisaje asociativo y organizativo, un dato por cierto, que en otros contextos los defensores del giro cultural de la historia social han señalado más de una vez para fundamentar su apuesta en favor de una revaloración de la antropología, la etnología o la psicología ante la casi omnipotente sociología, la politología y la economía como ciencias dominantes y principales herramientas del historiador social.

En segundo lugar, no resulta menos sorprendente la rapidez con la que los representantes políticos más lúcidos de la España postfranquista y el nacionalismo vasco moderado reencontraron, a pesar de los tremendos obstáculos a ambos lados, el camino del consenso que no era otro que el del Estatuto de Autonomía de 1979. Desde luego, la realidad postfranquista en el País Vasco no invitaba precisamente al consenso. Por una parte, la escalada de la actividad terrorista cada vez menos selectiva enrarecía el clima político y la ambigüedad del PNV ante estos actos de violencia daba alas a aquellas fuerzas del búnker para las que la solución del problema vasco pasaba necesariamente por la sumisión militar y policial de las provincias rebeldes del norte. Fueron justo los años de decisiones políticas de mayor envergadura en los que ETA incrementó al máximo su sangrienta actividad. Desde el primer atentado de 1968 hasta 1977 no se pasó nunca el máximo de 20 víctimas mortales anuales (1974). En los tres años posteriores con el referéndum constitucional (1978), el referéndum 
sobre el Estatuto de Gernika y las segundas elecciones generales (1979), así como las primeras elecciones al parlamento vasco (1980) un total de 240 personas murieron en atentados terroristas. Después, una vez tomadas estas decisiones y consolidada la democracia, la efectividad mortífera de ETA decreció nuevamente para establecerse entre 30 y 40 víctimas mortales al año. Entre 1968 y 1995 un total de 783 personas perdieron la vida como consecuencia de atentados terroristas de ETA.

AI PNV no le resultó fácil desvincularse de la violencia terrorista, dejar en el bául de los recuerdos los maximalismos y esencialismos y cambiar la mentalidad defensiva del exilio por una actitud ofensiva y flexible que aprovechara las nuevas posibilidades ofrecidas por la transición democrática. La marginación del partido de la ponencia constitucional, su abstención en los referéndums sobre la Ley de Reforma Política y sobre la Constitución, la a menudo desenfrenada actuación de las fuerzas de seguridad en las provincias vascas, así como la presión populista de la izquierda nacionalista en favor de una postura más exigente y radical, todo ello no auguraba nada bueno para el futuro de las relaciones entre el nacionalismo vasco y la España democrática.

La estrategia obstruccionista que los sectores más inmovilistas de la UCD mantuvieron durante las negociaciones en torno al Estatuto de Autonomia vasco suscitaron temores del mismo tipo. Aunque hoy en día quizás resulte anticuado y desde luego no muy propio de un historiador inspirado por la historia social y la sociologia histórica recalcar las aportaciones individuales y personales a la hora de explicar ciertos éxitos políticos, creo que en este caso - y espero que se me perdone esta licencia de rankeanismo puro- no se puede prescindir de una mención especial para el que entonces fue presidente del gobierno y lider de la UCD, Adolfo Suárez, por una parte, y el presidente del PNV y del Consejo General Vasco preautonómico Carlos Garaikoetxea. No sabemos qué hubiera ocurrido si estos dos hombres no hubieran alcanzado un acuerdo en aquella última ocasión que les quedó, durante esa interminable noche del 17 de julio de 1979. Gracias a lo que coloquialmente se suele denominar «buena química personal» y empujados por la convicción de que más allá del consenso se encontraba el peligroso abismo hacia la inestabilidad, el conflicto y la muerte, los dos políticos firmaron el preacuerdo que allanó el camino hacia la recuperación de la autonomía vasca aprobada el 25 de octubre por un $53 \%$ del censo de las tres provincias vascongadas con más del $90 \%$ de votos afirmativos. El Estatuto permitió al PNV mantener su exitoso discurso tradicional y seguir por donde habia terminado en 1936, es decir, como un partido nacionalista moderado plenamente integrado en el marco de la política española, que sin embargo no abandonaba sus creencias mi- 
lenaristas. La expresa referencia que en el Estatuto se hace a los "derechos históricos vascos" a los que los vascos no están obligados a renunciar a pesar de la aprobación de la autonomia, es la mejor prueba de ello. Da la impresión que la historia del nacionalismo vasco desde la elevación de la "reintegración foral plena» a la posición del máximo objetivo político en el primer programa del PNV de 1906, hasta la autodeterminación pasando por los derechos históricos, se presenta inevitablemente vinculada a este tipo de fórmulas vagas y de contenido muy discutible. Quizás no sea tan descabellada la idea defendida por los sectores más vasquistas del socialismo vasco de que una posible vía para desactivar el llamado contencioso vasco pase por un reconocimiento expresis verbis de estos derechos históricos vascos en el texto constitucional, cuya reforma no debería ser un tabú intocable. $Y$ es que en política a veces puede resultar más inteligente y eficaz explicitar menos las palabras y más los hechos.

Como resultado de este breve recorrido a través de 100 años de nacionalismo vasco llego por tanto a un escenario que a mí se me presenta de esta forma: el nacionalismo democrático del PNV y de Eusko A.lkartasuna es ampliamente mayoritario en el mundo nacionalista del País Vasco, acepta la pluralidad y su integración en el marco de la democracia parlamentaria española está fuera de duda. Las evocaciones independentistas, en el caso de EA incluso programáticas, son concesiones emocionales al pasado sin mayores repercusiones en la política diaria, en la que los políticos más lúcidos de ambos partidos se están dando cuenta de que en la era de la globalización de la aldea el concepto de independencia tanto vasca como española va perdiendo mucho del contenido que en el siglo XIX pudiera haber tenido. En consecuencia, el nacionalismo vasco ya no está obligado a mirar únicamente a Madrid (o a París), sino también y cada vez más a Bruselas, por lo cual a largo plazo previsiblemente bajará aún más la intensidad del enfrentamiento con el Estado, a no ser que éste intente obstaculizar drásticamente el flujo de comunicación entre Euskadi y Europa. Habrá que ver si las actualmente bastante fluidas relaciones entre el gobierno conservador y el PNV se traducen también en este campo en acuerdos de mutuo respeto y cooperación.

En el otro lado del escenario nacionalista vasco actual nos encontramos al nacionalismo de Herri Batasuna, ETA y KAS, al que no le separa su radicalidad del nacionalismo democrático - EA también defiende la independencia - sino su talante totalitario y su sumisión a la violencia. Aquí no ha habido evolución posibilista y la imagen de España (y de Francia) sigue siendo la que el primer Arana, y más tarde Krutwig, habian dibujado. La negativa a implicarse seriamente en las tareas institucionales - salvo a nivel municipal- obedece precisamente al temor de que el trabajo parla- 
mentario del día a día obligue a la concreción de los objetivos, para cuyo logro se requieren pactos, alianzas y concesiones mútuas, es decir, importantes dosis de gradualismo y posibilismo. Esto pondría en peligro la cohesión interna de ese mundo nada monolítico, cuyo máximo elemento vertebrador en la actualidad es ETA. Por esta misma razón también temo que probablemente habrá más interés en llegar a una solución del problema de la violencia dentro de la propia organización terrorista que en su entorno civil que vive y se nutre de la existencia de esta problemática. De todas formas, la grave crisis que vive el sistema político español debido a los numerosos casos de corrupción y de terrorismo de Estado, junto con unas tasas de desempleo realmente escandalosas sobre todo entre los jóvenes vascos, todo ello ha proporcionado enormes balones de oxigeno al nacionalismo violento, en un momento en que la pujanza del movimiento pacifista vasco estaba poniendo en tela de juicio la influencia de Herri Batasuna en muchos sectores de la sociedad tradicionalmente afines, sobre todo entre la juventud.

Como se ve, a lo largo de los últimos cien años, el nacionalismo vasco se ha diversificado, y con ello se han multiplicado las imágenes de y las posturas hacia España que existen entre los herederos de Sabino Arana. El nacionalismo democrático ha mantenido su indefinición programática e ideológica, pero ha acentuado una Realpolitik que le ha permitido ocupar una posición sólida, pero crítica y a veces distante dentro del sistema político español. El nacionalismo violento, en cambio, se ha aferrado a las esencias y al maximalismo. Sin embargo, su máximo punto de referencia y el elemento catalizador e integrador de esa gran coalición negativa no es la defensa de un determinado programa, sino la actividad de ETA. Aún no compartiendo las opiniones de aquellos que consideran a Sabino Arana como el primer instigador del terrorismo nacionalista - un terrorismo que tiene muchos padres, entre ellos el propio Franco- sí creo que por compartir raices históricas con el nacionalismo violento, el nacionalismo democrático tiene una responsabilidad especial en la dura tarea de pacificar Euskadi.

\section{BIBLIOGRAFIA BASICA}

Clark, Robert P.: The Basque Insurgents. ETA, 1952-1980, Madison 1984.

CORCuera, Javier: Origenes, ideologia y organización del nacionalismo vasco (1876-1904). Madrid 1979.

Elorza, ANTONIO: /deologias de/ nacionalismo vasco, 1876-1937, San Sebastián 1978.

Fusi, Juan Pablo: El Pais Vasco. Pluralismo y nacionalidad, Madrid 1984.

Garmendia, José Maria: Historia de ETA 1959-1974, 2 tomos, San Sebastián 1979/80.

GRANJA, JOSE LUIS DE LA: El nacionalismo vasco: un siglo de historia, Madrid 1995. 
Granja, José LUIS de LA: Nacionalismo y // República en el Pais Vasco. Madrid 1986.

GuRRUCHAGA, ANDER: El codigo nacionalista vasco durante el Franquismo, Barcelona 1985.

JAUREgUI, Gurutz: Ideologia y estratégia de ETA 1959-1968. Madrid 1981.

MeEs, Ludger; De Pablo, Santiago: "Historia social del nacionalismo vasco (1876-1937). Teoria y práctica de un movimiento social interclasista", en: Beramend, JuSto G.; Málz, RAMÓN; Núnez, Xosé M. (eds.): Nationalism in Europe. Past and Present, vol. Il, Santiago de Compostela 1994, 247-274.

MEES, LuDGER: Entre nación y clase. El nacionalismo vasco y su base social en perspectiva comparativa, Bilbao 1991.

MEES, LUDGER: "La izquierda imposible. El fracaso del nacionalismo republicano vasco entre 1910 y $1913 "$, Historia Contemporánea, 2, 1989, 249-266

MEES, LuDGER: Nacionalismo vasco, movimiento obrero y cuestión social (1903-1923), Bilbao 1992.

MEES, LUDGER: “Zwischen Euphorie und Depression. Der baskische Nationalismus 1917 bis 1953", in: Timmermann, Heiner (ed.): Die europäischen Nationalbewegungen 1914-1945. Berlin 1996 (en imprenta).

RIQUER, BOFJA DE: "Nacionalismo e historia. Sobre el lugar de los nacionalismos regionalismos en la historia contemporánea española". Historia Social, 7, 1990, 105-26.

SarRall.h de lhartza, FERnANDO (= F. Krutwig): Vasconia. Estudio dialéctico de una nacionalidad. Buenos Aires, $21973\{1963\}$.

SCHULZE, HAGEN: Staat und Nation in der Europäischen Geschichte, München 1994.

TILLy, ChaRLES (Ed.): The Formation of National States in Western Europe, Princeton 1975.

VILAR, PIERRE: “Estado, nación, patria en España y en Francia 1870-1914", Estudios de Historia Social, 28/29, 1984, 7-41.

WALDMANN, PETER: Ethnischer Radikalismus. Ursachen und Folgen gewaltsamer Minderheitenkonflikte am Beispiel des Baskenlandes, Nordirlands und Quebecs, Opladen 1989.

Weber, Eugen: Peasants into Frenchmen, Stanford 1976. 